\title{
Application of Factorial Design of Experiments for the Continuous Hydrogenation of Enriched Castor Oil Methyl Esters
}

\author{
T.S.V.R. Neeharika1, K.N.P. Rani1*, K.V.S.A. Rao ${ }^{1}$, T.P. Kumar ${ }^{2}$, R.B.N. Prasad1 \\ ${ }^{1}$ Centre for Lipid Research, Indian Institute of Chemical Technology, Hyderabad - 500007, India \\ ${ }^{2}$ Chemical Engineering Division, Indian Institute of Chemical Technology, Hyderabad - 500007, India
}

Received: 2nd September 2013; Revised: 4th October 2013; Accepted: 5th October 2013

\section{Abstract}

Castor oil methyl esters contains nearly 90\% ricinoleic acid (12-hydroxy-cis-9-octadecenoic acid). Hydrogenated castor oil methyl esters finds several applications in coating, lubricants formulations and pharmaceutical areas. The present study reports a fast, simple, efficient and continuous hydrogenation of enriched castor oil methyl ester (ECME) using $10 \% \mathrm{Pd} / \mathrm{C}$ catalyst at different pressures and temperatures. The range of process conditions for this study varied from $30-60{ }^{\circ} \mathrm{C}, 5-15$ bar with constant flow rate of 15 $\mathrm{ml} / \mathrm{min}$. The products were analyzed for fatty acid composition and iodine value (IV). The optimized parameters were found to be a temperature of $30{ }^{\circ} \mathrm{C}$, pressure $5 \mathrm{bar}$, and flow rate of $15 \mathrm{ml} / \mathrm{min}$ where maximum hydrogenation of $98.47 \%$ was obtained and the product showed an iodine value of 3.19. (C) 2013 BCREC UNDIP. All rights reserved

Keywords: enriched castor oil methyl ester; hydrogenated castor oil methyl ester; continuous hydrogenation; 12-hydroxy stearic acid; design of experiments

How to Cite: Neeharika, T.S.V.R., Rani, K.N.P., Rao, K.V.S.A., Kumar, T.P., Prasad, R.B.N. (2013). Application of Factorial Design of Experiments for the Continuous Hydrogenation of Enriched Castor Oil Methyl Esters. Bulletin of Chemical Reaction Engineering \& Catalysis, 8 (2): 154-159.

(doi:10.9767/bcrec.8.2.5375.154-159)

Permalink/DOI: http://dx.doi.org/10.9767/bcrec.8.2.5375.154-159

\section{Introduction}

Global castor seed production is around one million tons per year and India is the major producer and exporter of castor oil (with over three-quarters of the global yield). The seed production is estimated to be over 8,30,000 tons per year on an average. Castor oil is the only commercial source of un-

* Corresponding Author.

E-mail: knpr@iict.res.in (K.N.P. Rani),

Tel: +91-40-27191838 , Fax: +91-40-27193370 saturated hydroxyl acid (12-hydroxy-cis-9octadecenoic acid) that is ricinoleic acid to the extent of $85-90 \%$ which is the feedstock for many of the useful industrial chemicals. Ricinoleic acid has 18 carbon on its backbone with one hydroxyl group on the $12^{\text {th }}$ carbon atom and it also has a cis double bond between the $9^{\text {th }}$ and $10^{\text {th }}$ carbon atoms. Castor oil is mostly used in the form of its modified derivatives such as dehydrated, hydrogenated, alkoxylated, sulphated and the halogenated derivatives [1].

Castor oil is used in the manufacture of various 
products like hydrogenated castor oil (HCO), dehydrated castor oil (DCO) and its fatty acids, etc. Castor oil is also used in a wide range of cosmetics, toiletries and transparent soaps. Castor oil and its derivatives are also used in lubricating formulations. Many of the industrial castor-based chemicals are made either with castor oil/castor fatty acids or mostly its methyl esters (CME) as such containing $85-90 \%$ ricinoleic content.

HCO is a hard, brittle waxy material that is insoluble in water and is used in pharmaceutical formulation as a sustained release coating material and hardening agent $[2,3]$ mainly used in preparation of plastic auxiliary agents, lubricants, surfactants, coatings, printing inks, etc, and is the only material to produce 12-hydroxystearic acid. 12hydroxystearic acid is one of the most important materials to produce lithium lubricating grease. It is also widely used in coatings, resins, plastics, daily chemical products, pharmaceutical industries, etc.

Some researchers worked on batch hydrogenation of castor oil [3-8], however, not much literature is reported on continuous hydrogenation of CME or ECME [9]. Enriched ricinoleic content with more hydroxyl value is an added advantage in the preparation of many useful industrial products with enhanced desired properties. Major advantage of this process is ECME upon hydrogenation, yields a hydrogenated product less in impurities, that can be a potential candidate as a raw material for different industrial applications. Hence for the first time this work reports a rapid, continuous and efficient process for hydrogenation of ECME using a continuous flow hydrogenator. This process is advantageous because the catalyst is held stationary as a fixed bed column where the interactions between feed and hydrogen takes place and the need to filter catalyst is avoided unlike conventional hydrogenation [10]. However time taken for hydrogenation using the described method was much less compared to conventional method. Further the product can be obtained directly without any filtration unlike the conventional method. The parameters for hydrogenation of ECME were optimized. Experimental designs gives an insight about the mathematical relationship between the factors and the response. A thorough literature survey of application of factorial design of experiments has been applied by quite a few researchers [11-13].

This work reports the continuous hydrogenation of ECME with the application of design of experiments to interpret the results. The main objective of this work was to study the effect of reaction parameters such as temperature, $\mathrm{H}_{2}$ pressure on the conversion for the continuous hydrogenation of ECME.

\section{Materials and Methods}

\subsection{Materials}

ECME used in the experiments contained 96.67\% methyl ricinoleate (MR), with hydroxyl value of 172.1 and iodine value of 84.5. Methanol used in the experiments was of analytical grade and was procured from M/s. Sd Fine chem. Pvt. Ltd., Mumbai.

\subsection{Methods}

The fatty acid composition of ECME and hydrogenated ECME was analyzed using Gas Chromatograph Agilent 6890 series equipped with flame ionization detector. The stationary phase used was a capillary column, HP1 MS (ID $0.25 \mathrm{~mm}$, length $30 \mathrm{~m})$. The oven temperature was programmed from 150 to $300{ }^{\circ} \mathrm{C}$ at $10{ }^{\circ} \mathrm{C}$ per minute and nitrogen with a flow rate of $35 \mathrm{ml} / \mathrm{min}$ was used as carrier. The injector and detector temperatures were maintained at 280 and $300{ }^{\circ} \mathrm{C}$ respectively. The area percentage was recorded using HP Chem Station Data System. ECME contained stearic $(0.377 \%)$, oleic $(0.91 \%)$, linoleic $(1.641 \%)$, methyl ricinoleate $(96.67 \%)$ and dihydroxy $(0.40 \%)$ fatty acids. Iodine value of the samples was determined using standard AOCS Method [14]. The conversion was calculated both by Gas Chromatography (GC) and Iodine Value (IV).

A continuous hydrogenator (Thales Nano, Hungary) was used for the hydrogenation of ECME. The H-Cube Midi ${ }^{\mathrm{TM}}$ is a compact, high-pressure (up to 100 bar), hydrogenator with built in technology to generate hydrogen by electrolysis of water [10]. It comprises cartridge to hold the catalyst. The hydrogenation process takes place exclusively inside the catalyst cartridge.

\subsection{Experimental Procedure}

Hydrogenation of ECME was accomplished by employing a continuous flow hydrogenator as shown in Scheme 1 using prepacked catalyst cartridge containing $10 \% \mathrm{Pd} / \mathrm{C}$. The degree of conversion was monitored by determining the composition and iodine value of product after hydrogenation.

Feed is pumped using a HPLC pump where it gets combined with the hydrogen gas generated in situ by electrolysis of water, the mixture was then preheated to reaction temperature and was allowed to pass through the cartridge containing the prepacked catalyst, where the actual reactions take place and the product stream was cooled by passing through a heat exchanger and collected at the receiver provided.

The hydrogenation of ECME on $10 \% \mathrm{Pd} / \mathrm{C}$ 
yielded 12 hydroxy stearic acid as the main product. Small amounts $(<5 \%)$ of stearic acid were observed which is due to simultaneous dehydration. Scheme 2 shows the reaction route of ricinoleic acid hydrogenation.

The hydrogenator was initially stabilized by taking a blank run using methanol only. Then the system was pressurized to 5 bar at a temperature of $60{ }^{\circ} \mathrm{C}$ with methanol. Reaction mixture containing ECME, methanol in ratio 1:19 (5 ml of ECME in $95 \mathrm{ml}$ of methanol, vol ratio) was homogenized and allowed to pass through prepacked cartridge containing $10 \% \mathrm{Pd} / \mathrm{C}$ catalyst at different temperatures, pressures. The sample was collected, desolventized and dried under reduced pressure for further analysis. The fatty acid composition was determined using GC and the amount of unsaturation was determined by IV. All the conversions were calculated based on GC composition and is shown below:

$$
\text { Conversion }(\%)=\left\{1-\left(M R_{\text {final }} / M R_{\text {initial }}\right)\right\} \times 100
$$

\subsection{Statistical Analysis}

A $2^{2}$ (two level two factor) factorial design of experiments have been used for this study. The response was measured as Y (conversion of MR) and the factors chosen were temperature $\mathrm{X}_{\mathrm{T}}$, and pressure $X_{P}$. The design matrix for the factorial design and the results of conversion are shown in Table 1. The experiments were run at random and in triplicates for experimental error estimation.

\section{Results and Discussion}

The effect of operating parameters, such as pressure and temperature on hydrogenation of enriched castor oil methyl esters, has been studied and factorial design of experiments was applied for optimization of the process.

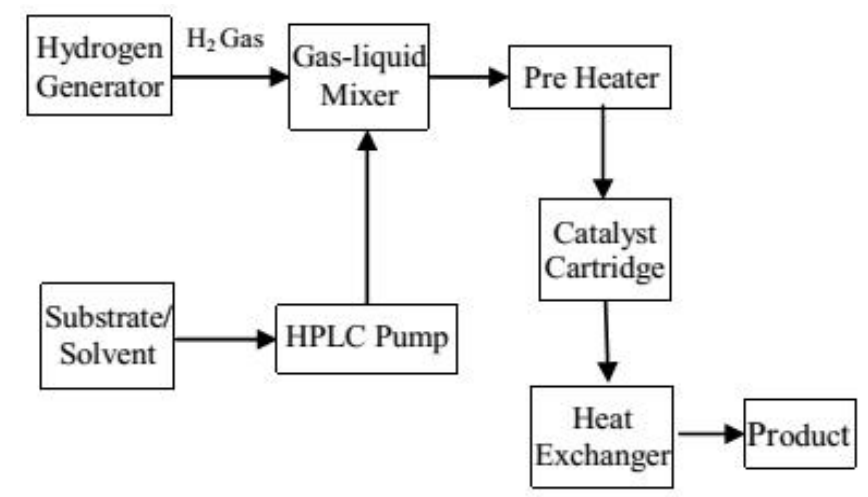

Scheme 1: Block diagram of the continuous hydrogenator
Several tests were carried out initially with different levels of pressure and temperature to arrive at a reasonable conversion. Based on these results and the operational limits of the experimental set up, the temperature and pressure levels were set as 30 and $60^{\circ} \mathrm{C}$ and 5 and 15 bar. The flow rate of feed was maintained at $15 \mathrm{ml} / \mathrm{min}$. As seen in Figure 1 an increase in temperature from 30 to $50^{\circ} \mathrm{C}$ decreased the conversion of methyl ricinoleate from $98.47 \%$ to $97.29 \%$ and on further increase in temperature to $60{ }^{\circ} \mathrm{C}$, conversion drastically reduced to $93.52 \%$. The conversion of methyl ricinoleate obtained for different pressures is shown in Figure 2, it is observed that as pressure increased from 5 bar to 10 bar the conversion decreased from $98.47 \%$ to $96.64 \%$ and further increase in pressure to 15 bar decreased the conversion to $95.40 \%$. However, a further increase in the pressure to 15 bar did not produce any significant change in the conversion rate. The conversions were also evaluated using iodine value and the values are graphically represented for comparison only.

A statistical analysis was carried out on the experimental results to determine the main effects

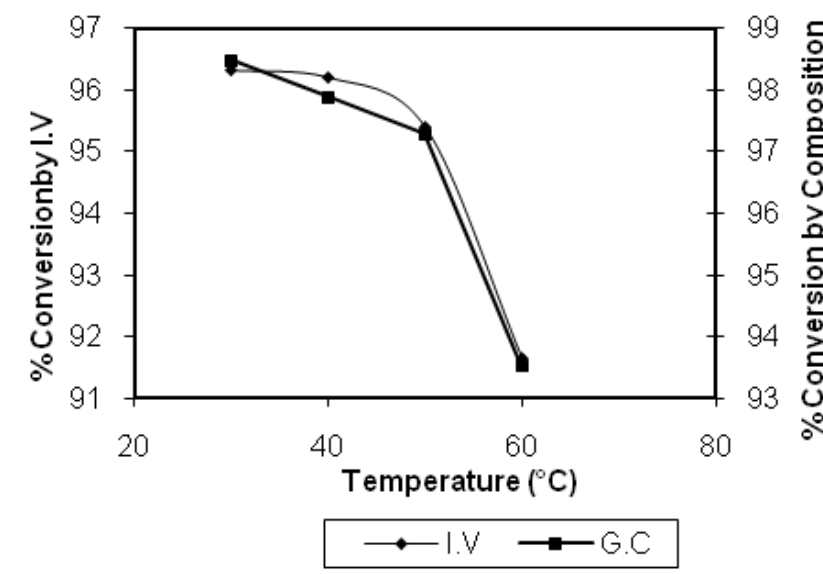

Figure 1. Effect of temperature on conversion of ECME at 5 bar pressure and $15 \mathrm{ml} / \mathrm{min}$ flow rate

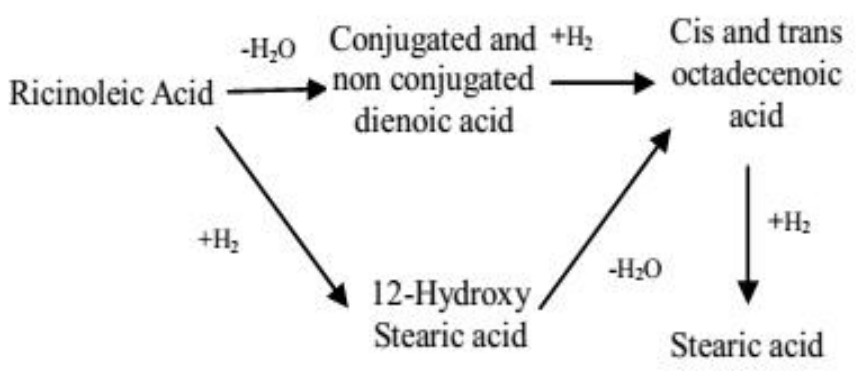

Scheme 2: Hydrogenation of ricinoleic acid 
and the interaction effect. The ANOVA for the response surface model is shown in Table 2. It can be inferred that both pressure and temperature are the significant factors as they showed a negative influence on conversion, most probably, because of the formation of side product (stearic acid formation). Also it is observed that the p-value is less than 0.05 which indicates that there is a statistical relation between the response and the selected variables at $95 \%$ confidence level.

The following model was obtained upon regression and test for the fit of the model was carried out by evaluating the determination coefficient $\left(\mathrm{R}^{2}\right.$ $=0.9623)$. The predicted $R^{2}$ value $(0.9151)$ was in good agreement with adjusted $R^{2}$ value (0.9481):

$$
\begin{aligned}
Y= & 104.9967-0.34333 X_{P}-0.20606 X_{T}+ \\
& 0.0040111 X_{P} X_{T}
\end{aligned}
$$

Figure 3 shows the residual distribution over the observed values for the response studied. A good fit was observed for this study because the residual distribution does not follow a trend with regard to the predicted variables. The model accurately represents the influence of conversion over the experimental range studies as all the residuals are less than 1.5 and the same is proved by the plot of experimental values vs. predicted values as shown in Figure 4.

Figure 5 which shows the random distribution of the residuals depicts a trendless behavior, thus strengthening the fact that the proposed mathematical model explains the relation between experimental and calculated values. The comparison of the experimental and calculated responses for

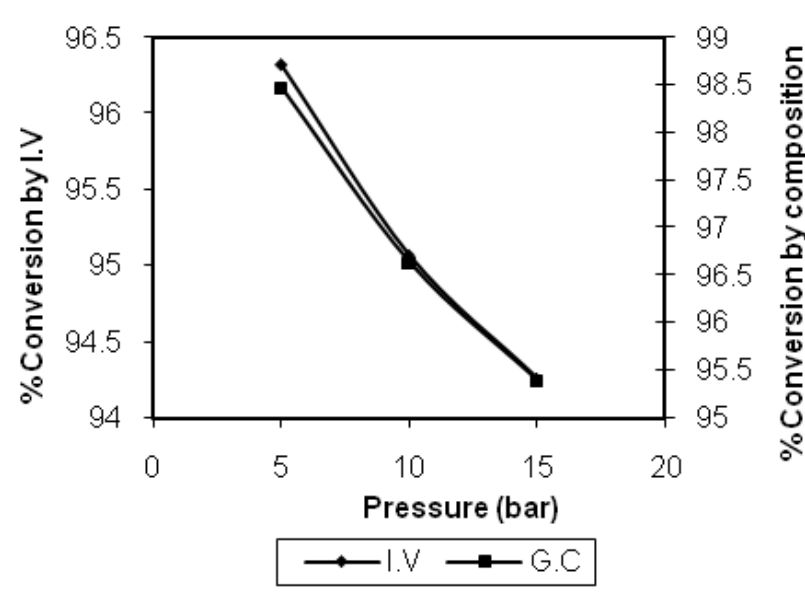

Figure 2. Effect of pressure on conversion of ECME at $60^{\circ} \mathrm{C}$ and $15 \mathrm{ml} / \mathrm{min}$ flow rate

Table 1. Experimental design matrix

\begin{tabular}{ccccc}
\hline $\begin{array}{c}\text { Experiment } \\
\text { Number }\end{array}$ & Order & $\begin{array}{c}\text { Pressure } \\
\text { (bar) }\end{array}$ & $\begin{array}{c}\text { Temperature } \\
\left({ }^{\circ} \mathbf{C}\right)\end{array}$ & $\begin{array}{c}\text { Conversion } \\
(\mathbf{\%})\end{array}$ \\
\hline 1 & 6 & 5 & 30 & 98.47 \\
2 & 1 & 5 & 30 & 97.28 \\
3 & 3 & 5 & 30 & 97.5 \\
4 & 4 & 15 & 30 & 95.4 \\
5 & 2 & 15 & 30 & 96.05 \\
6 & 9 & 15 & 30 & 94.96 \\
7 & 10 & 5 & 60 & 92.52 \\
8 & 12 & 5 & 60 & 91.69 \\
9 & 7 & 5 & 60 & 92.15 \\
10 & 5 & 15 & 60 & 91.85 \\
11 & 8 & 15 & 60 & 90.18 \\
12 & 11 & 15 & 60 & 91.25 \\
\hline
\end{tabular}

Table 2. ANOVA for response surface linear model

\begin{tabular}{lccccc}
\hline \multicolumn{1}{c}{ Source } & Sum of Squares & df & Mean Square & F Value & p- value \\
\hline Model & 83.39 & 3 & 27.80 & 68.00 & $<0.0001$ \\
A-pressure & 7.95 & 1 & 7.95 & 19.46 & 0.0023 \\
B temperature & 74.35 & 1 & 74.35 & 181.88 & $<0.0001$ \\
AB & 1.09 & 1 & 1.09 & 2.66 & 0.1418 \\
Pure Error & 3.27 & 8 & 0.41 & & \\
Cor Total & 86.66 & 11 & & & \\
\hline
\end{tabular}


the model show the agreement between the observed and predicted values. The figure shows that the mathematical model used for the prediction of the response provides good agreement for the experimental data. Figure 5 shows the normal probability plot of the residuals indicating a good validity for the linear regression model. Figure 6 shows the $3 \mathrm{D}$ response surface graph of the regression equation and the contour plot is given in Figure 7.

\subsection{Evaluation of Rate Equation}

Based on the data, the rate constant was determined for this system by the following Equation:

$$
C_{A o}=\frac{N_{A o}}{V}=\frac{p_{A o}}{R T}
$$

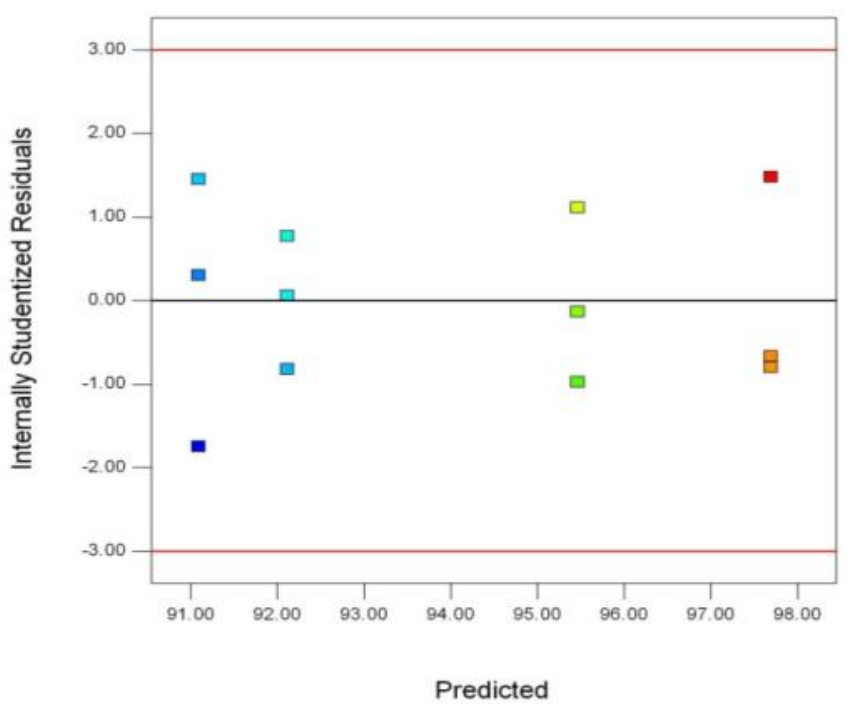

Figure 3. Residual plots of conversion for the model

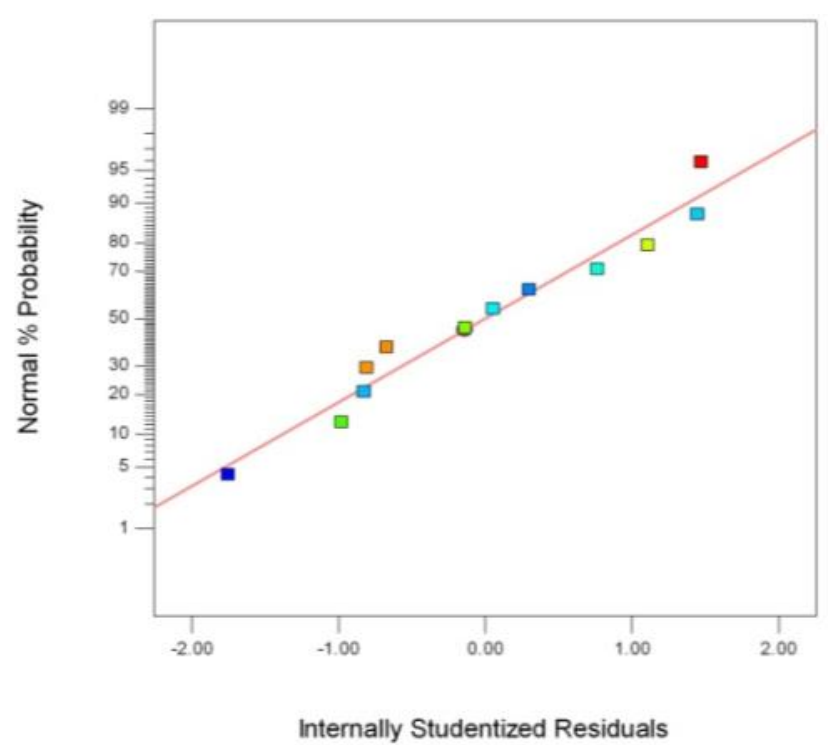

Figure 5. Normal probability plot of residuals

$$
F_{A o}=C_{A o} v
$$

where $C_{A o}$ denotes the initial concentration of MR, $C_{A}$ denotes the concentration of $\mathrm{MR}, P_{A o}$ is the pressure and $T$ is the reaction temperature, respectively.

$$
X_{A}=\frac{1-C_{A} / C_{A o}}{1+\varepsilon_{A}\left(C_{A} / C_{A o}\right)}
$$

Similarly $\mathrm{X}_{\mathrm{A} \text { in }}$ and $\mathrm{X}_{\mathrm{A} \text { out }}$ are calculated and substituted in the Equation (5).

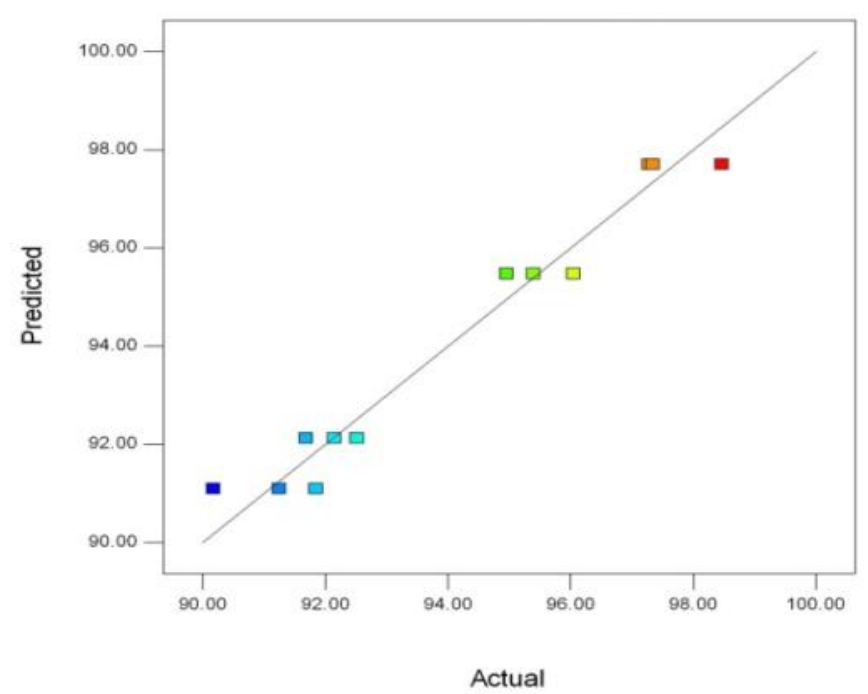

Figure 4. Predicted values vs. experimental values for the model

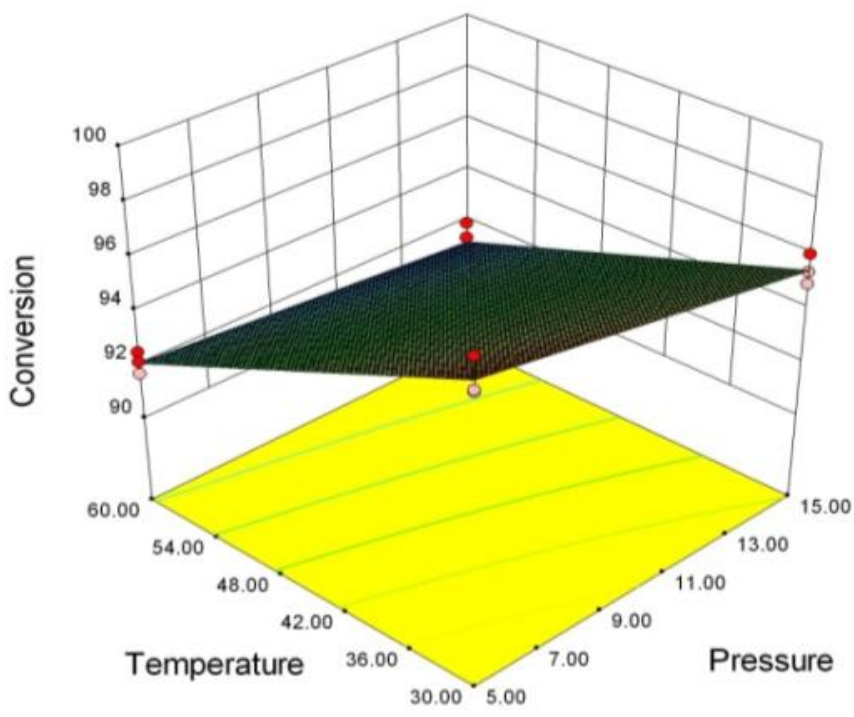

Figure 6. Response surface plot of conversion as a function if temperature and pressure 


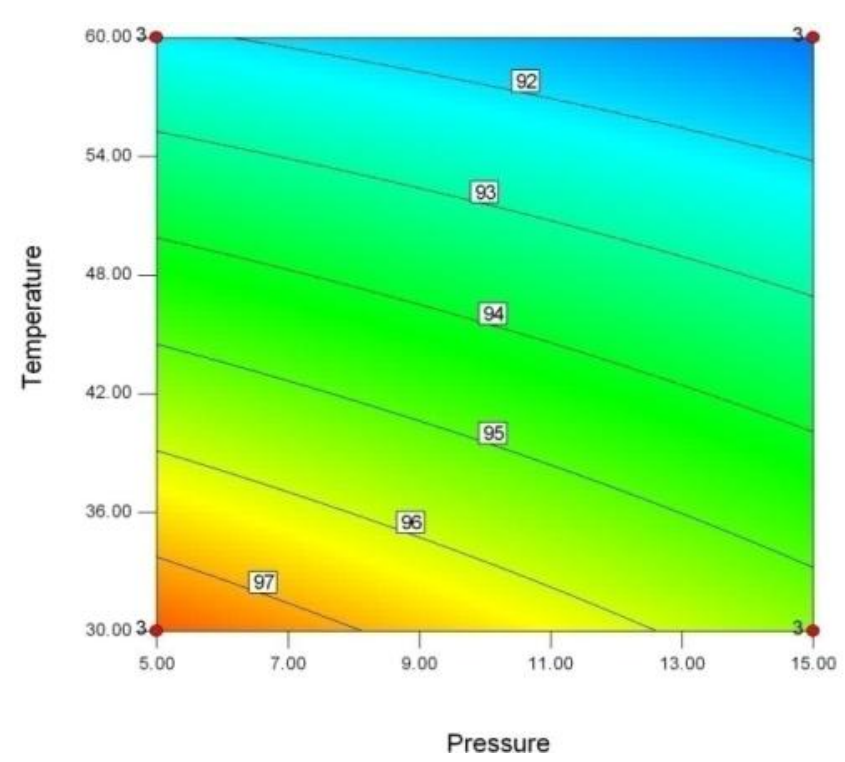

Figure 7. Contour plots of conversion as a function if temperature and pressure

$$
-r_{A}{ }^{\prime}=\frac{\Delta X_{A}}{W / F_{A o}}
$$

where $\Delta X_{A}$ denotes change in conversion, $W$ is the mass of catalyst. Substituting the values the final rate equation for the system is given by:

$$
-r_{A}{ }^{\prime}=\frac{1}{W} \frac{d N_{A}}{d t}=19.73 \frac{\mathrm{mol}}{\text { hr. kgcat }}
$$

\section{Conclusion}

The process reported is a simple, quick and efficient method for the continuous hydrogenation of ECME. Hydrogenation of ECME decreased with increase in temperature and pressure. The optimized conditions for hydrogenation of ECME using $10 \% \mathrm{Pd} / \mathrm{C}$ as a catalyst are a pressure of 5 bar, temperature $30{ }^{\circ} \mathrm{C}$ and flow rate of $15 \mathrm{ml} / \mathrm{min}$. A $2^{2}$ factorial design of experiments have been employed for the process optimization.

\section{Acknowledgement}

The funding by National Agricultural Innovation Project is gratefully acknowledged.

\section{References}

[1] Patel, B.P., Patel, H.S., Patel, S.R. (2004). Modified castor oil as an epoxy resin curing agent. $E$ Journal of Chemistry, 1: 11-16.
[2] Osaka, T.S., Hyogo, T.T., Osaka, Y.S. (1991). Sustained-release preparations and the process thereof. US Patent No. 5,023,089.

[3] Romtman, A., Blatt, Y. (1992). Heat stabilized flavoring agents coated with hydrogenated castor oil. US Patent 5,098,725.

[4] Sreenivasan, B., Kamath, N. R., Kane, J. G. (1957). Studies on castor oil. II. Hydrogenation of castor oil. Journal of the American Oil Chemists' Society, 34: 302-307.

[5] Trivedi, R.K., Vasishtha, A.K. (1988). Low pressure hydrogenation of castor oil. Journal of the American Oil Chemists' Society, 65: 14671469 .

[6] Trivedi, R.K., Vasishtha, A.K. (1997). Effect of agitation in the hydrogenation of castor oil. Journal of the American Oil Chemists' Society, 74: 957-962.

[7] Martinelli, M., Schneider, R.C.S., Baldissarelli, V.Z., von Holleben, M.L.A., Caramao, E.B., (2005). Castor oil hydrogenation by a catalytic hydrogen transfer system using limonene as hydrogen donor. Journal of the American Oil Chemists' Society, 82: 279-283.

[8] Vishwanadham, B., Khan, A. A., Bhagvanth, Rao M. (1995). Reaction rates of simultaneous dehydration and hydrogenation of castor oil. Journal of the American Oil Chemists' Society, 72: 1033-1036.

[9] Rao, K.V.S.A, Vijayalakshmi, P., Prasad, R.B.N, (2009). A process for the enrichment of methyl ricinoleate from castor oil methyl esters by liquidliquid extraction. WO 2009/109985/ A1.

[10] Jones, R.V, Godorhazy, L., Varga, N., Szalay, D., Urge, L., Darvas, F. (2006). Continuous-flow high pressure hydrogenation reactor for optimization and high-throughput Synthesis. Journal of Combinatorial Chemistry, 8: 110-116.

[11] Berrios, M., Gutierrez, M.C., Martin, M.A., Martin, A. (2009). Application of the factorial design of experiments to biodiesel production from lard. Fuel Processing Technology, 90: 1447-1451.

[12] Boulifi, N.El., Bouaid, A., Martinez, M., Aracil, J. (2010). Process optimization for biodiesel production from corn oil and its oxidative stability. International Journal of Chemical Engineering, Article ID 518070, 9 pages.

[13] Cepeda, E.A., Calvo, B. (2008). Sunflower oil hydrogenation: Study using response surface methodology. Journal of Food Engineering, 89: 370-374.

[14] Firestone, D. Iodine value. Cd 1-25. In Official Methods and Recommended Practices of the American Oil Chemists' Society, 4th ed.; American Oil Chemists' Society Press: Champaigne, IL, 2004. 